\title{
Uso de Jogo Online no Apoio ao Processo de Alfabetização Infantil - Programa Domlexia
}

\author{
Nadine Heisler, Sabrina Vieira da Luz 1 \\ 1 Domlexia - Rua Laurindo Januário da Silveira, 4317/5 \\ CEP 88062-201- Florianópolis - SC - Brasil \\ nadine@domlexia.com.br, sabrinaddomlexia.com.br
}

\begin{abstract}
The present work describes a proposal of an online game to support literacy for children at risk of dyslexia based on phonological awareness. The Domlexia program, formulated to be used with the whole 1st grade class of elementary school, also integrates an assessment activity at each stage of the game, which allows a follow-up of the students' development and traces a profile of the progress of literacy. A prototype test of the game was realized in two public classes of $1_{\text {st }}$ grade and the results demonstrated improvement in the tests of phonological awareness after one month of use of the game.
\end{abstract}

Resumo: O presente trabalho descreve uma proposta de um jogo online de apoio à alfabetização para crianças com risco de dislexia com base na consciência fonológica. O programa Domlexia formulado para ser utilizado com toda a turma de $1^{\circ}$ ano do Ensino Fundamental também integra uma atividade de avaliação em cada etapa de jogo, que permite um acompanhamento do desenvolvimento dos alunos e traça um perfil do progresso da alfabetização. Foi realizado um piloto de aplicação do jogo em duas turmas de alfabetização e os resultados demonstraram melhora nos testes de consciência fonológica após um mês de uso do jogo.

\section{O Problema}

Dez a $15 \%$ da população tem dislexia [Clarck, 1995]. No Brasil, o número de diagnósticos é ainda muito pequeno e a própria complexidade de fazê-lo leva ao fato de que muitos passam toda sua vida escolar sem saber que são disléxicos e, portanto, sem a intervenção correta [Ellis, 1995].

Esse fato, como reportado em outros países [Coulter and Kaloi 2013], leva a defasagem e a evasão escolar. Indo além, estudos reportam que a não intervenção/apoio levam a criminalidade e abuso de álcool e drogas [Rack,2005]. De forma prática, no Brasil, ainda há poucas oportunidades de realização de diagnóstico da dislexia, principalmente em função da complexidade deste, que precisa ser realizado por equipe multidisciplinar. Como consequência, muitos alunos passam pela escola sem a identificação de suas dificuldades para a aquisição da leitura e escrita.

Essa falta de informação é ainda agravada pelo baixo conhecimento dos profissionais envolvidos sobre o tema, uma vez que os transtornos de aprendizagem não são parte regular do currículo de formação de pedagogos. 
A pesquisa ANA 2016 (Avaliação Nacional de Alfabetização - INEP) mostra que $55 \%$ dos alunos do $3^{\circ}$ ano do Ensino Fundamental tem leitura insuficiente para a idade [Brasil,2019]. Já a Prova Brasil 2017, mostra que apenas 56\% dos alunos brasileiros do $5^{\circ}$ ano do Ensino Fundamental tem proficiência considerada adequada [QEdu, 2019]. Esses dados mostram que há bastante espaço para melhorias e uso de ferramentas que venham fortalecer o processo de alfabetização.

\section{Objetivo}

Contribuir de forma positiva para as ações pedagógicas de alfabetização, apoiando o processo através de atividade tecnológica, lúdica e interativa; não somente para crianças com risco de dislexia, mas para todos os estudantes com dificuldade de aprendizado.

\section{Público-Alvo}

Alunos do $1^{\circ}$ ano do Ensino Fundamental das redes públicas e privadas, em início do processo de alfabetização. O programa é adequado aos alunos com ou sem dificuldades de aprendizado.

\section{Justificativa}

Diversos estudos científicos trazem a comprovação de que o método fônico, no qual se ativa a consciência fonológica, tem grande eficácia como base sólida para aquisição da leitura e escrita.

O método fônico traz benefícios para as crianças, que passam a ser alfabetizadas mais rápidas e é eficaz na compreensão e produção textual, pois fortalece o raciocínio e a inteligência verbal [Capovilla, 2010]. O objetivo de se trabalhar com a consciência fonológica é que o aluno passa a fazer correspondência entre grafema-fonema, com o objetivo de trabalhar a leitura e a soletração [Henning, 2003].

Podemos citar o trabalho, da Universidade de Stanford - EUA [McCandllis 2003], que monitorou a atividade cerebral de crianças que estavam aprendendo através da relação grafema/fonema ativaram as áreas cerebrais relacionadas à leitura e escrita, enquanto que aquelas que trabalharam o reconhecimento de palavras como primeira abordagem estavam ativando o hemisfério direito, trazendo evidências da ativação das rotas de linguagem através da relação grafema/fonema.

Em relatório a Academia Nacional Norte Americana recomenda que o ensino da linguagem deve ser amplo, mas que em seu início, a conscientização da relação de fonemas e grafemas, não prejudica nenhum aluno, e pelo contrário é essencial para diversos deles.

Em trabalhos mais antigos de 1967 [Chall 1996], a autora já havia esse olhar. Ela fez uma ampla revisão sobre a bibliografia de ensino de 1910 a 1965, concluindo que a abordagem inicial com ênfase no aprendizado da relação entre letras e sons produzem resultados melhores do que os outros métodos.

Não se trata de substituir um método por outro, mas sim aproveitar o que cada proposta tem de melhor e ofertar aos alunos as mais diversas possibilidades. O ideal é identificar as dificuldades de método e mesclar o que há de eficiente nas duas correntes metodológicas, trabalhando com a alfabetização contextualizada simultaneamente ao desenvolvimento da consciência fonológica [Santos, 2018]. Optamos assim por nos apropriar dos conceitos fonológicos da relação entre grafemas e fonemas e através do elemento lúdico trazê-los para o mundo infantil. 


\subsection{O Lúdico como abordagem de aprendizado}

É sabido que boa parte da resistência em relação à fônica se deve à falta de contexto do método e a complexidade do ensino. Buscamos então, através do Programa, quebrar essas barreiras pela utilização de jogo online, que traz a linguagem atual e atraente para os alunos, além de ser extremamente fácil de ser acompanhada pelo professor.

O lúdico é valorizado como forma de aprendizado pelos grandes teóricos e estudiosos da pedagogia, que avaliam a sua importância para o aprendizado e retenção do conhecimento. $\mathrm{O}$ brincar é a linguagem típica da criança, por ser mais expressiva que a linguagem verbal, foi atribuído ao jogo um papel de complemento imprescindível à análise da criança [Piaget 1998]. A brincadeira é universal e é própria da saúde. Há a necessidade de se usar a ludicidade com mais intensidade, pois o brincar facilita $\mathrm{o}$ crescimento e conduz aos relacionamentos grupais [Vigotsky 2001].

\subsection{Aprendizado ativo}

A tese do norte-americano Roger Schank, crítico do modelo tradicional de educação, segundo o qual o verdadeiro aprendizado vem da prática, não das teorias de sala de aula, foi o que inspirou o Programa Domlexia a incluir além do jogo, atividades mão na massa, cinestésicas, onde os alunos podem vivenciar o trabalho em grupo, aprender a ter uma escuta ativa e empatia; além de trazer a oportunidade de "construir" as letras usando a criatividade e a imaginação [Schank, 2019].

\subsection{BNCC - Base Nacional Comum Curricular}

A BNCC [BRASIL, 2018] vem a dar as diretrizes para a educação brasileira. Traz em seu corpo, logo ao princípio, 10 competências que devem ser desenvolvidas ao longo da vida escolar, como: utilizar conhecimentos das diferentes linguagens (oral, escrita, LIBRAS, corporal, entre outras).

Já revela a importância de se formar desde cedo a capacidade de comunicação através do uso das linguagens, incluindo a linguagem escrita que aqui buscamos dar bases sólidas. As atividades cinestésicas em grupo, propostas pelo Programa Domlexia, endereçam já no início do Ensino Fundamental 1 outra competência citada na Base: exercitar a empatia, o diálogo, a resolução de conflitos e a cooperação.

Especificamente em relação ao $1^{\circ}$ ano do Ensino Fundamental, na área da Língua Portuguesa, a BNCC estabelece no Eixo de Conhecimentos Linguísticos e Gramaticais, na Unidade Temática de Apropriação do Sistema Alfabético e de Escrita habilidades a serem desenvolvidas que são trabalhadas intensamente pelo Programa Domlexia, como o reconhecimento do sistema de escrita alfabética como representação dos sons da fala, comparar palavras identificando semelhanças e diferenças entre sons de sílabas iniciais, identificar fonemas e sua representação por letras, completar palavras com letra inicial, com base na escuta da palavra ou desenho que a represente, nomear as letras do alfabeto e escrever as letras do alfabeto em resposta ao nome da letra.

\section{Ferramenta Desenvolvida}

Um jogo para celular/tablete foi desenvolvido, usando linguagem Unity, compatível com web, IOS e Android. Baseado em exercícios de conscientização fonológica [Savage 2015], permitindo aos estudantes de 6 a 8 anos, em fase de alfabetização, no $1^{\circ}$ ano do Ensino Fundamental familiarização com os principais fonemas e letras da língua portuguesa e o estabelecimento de uma relação com a escrita (grafia) dos mesmos. O jogo educacional permite uma interação lúdica com o processo de alfabetização, 
conduzido pelo simpático dragão Dom. Ao final de cada uma das cinco fases do jogo, chamadas "mundos", há uma atividade de avaliação, que permite um acompanhamento do desenvolvimento do aluno ao longo do jogo. Além do uso do jogo, são propostas atividades cinestésicas para sala de aula, com abordagem concreta, fornecendo uma nova possibilidade de fixação do aprendizado.

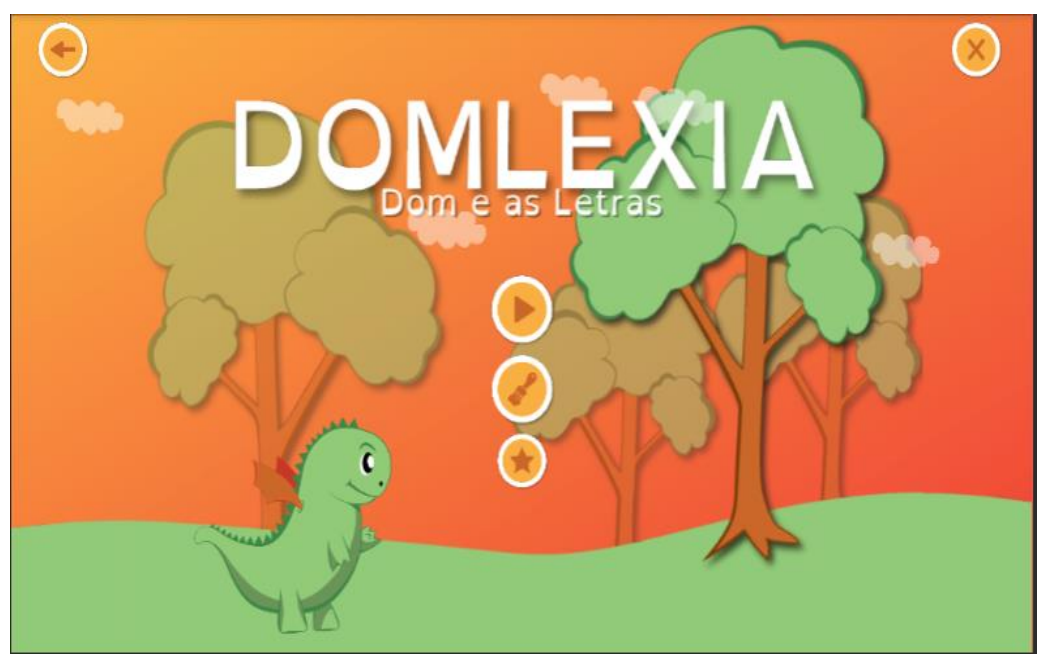

Figura 1: Tela inicial do jogo

O Jogo Dom é composto por cinco mundos, cada um com um grupo de letras, reunindo os primeiros fonemas a serem trabalhados na alfabetização fônica. Estão assim divididos:

Mundo 1 - A, E, I, O, U

Mundo 2 - B, P, D, T

Mundo 3 - F, V, S, X, Z

Mundo 4 - M, N, L, R

Mundo 5 - C, Q, G, J

Em cada mundo, cada letra possui três mini-games.

Mini-game 1 - Propõe o reconhecimento da letra escrita e sua relação com o som do "nome" da letra. Cada vez que o jogador clica sobre uma das letras, ouve o seu nome e visualmente vai relacionando a mesma, com a letra que está sendo trabalhada.

Mini-game 2 - Trabalha a relação do som do fonema e o início da palavra (objetos do cotidiano da criança). Os jogadores podem ouvir a palavra e o fonema quantas vezes desejar, além de ter o apoio visual com a imagem da referida palavra. $\mathrm{O}$ jogador então escolhe se a palavra em questão se inicia ou não com o fonema que está sendo trabalhado.

Mini-game 3 - Neste terceiro desafio, o jogador deve reconhecer visualmente se a palavra apresentada (sem som) tem em seu início o fonema trabalhado (com recurso sonoro). Assim ele vai escolhendo se o fonema está ou não no início da palavra apresentada. Após completar o mundo, é apresentado um desafio final ao jogador. Nesse desafio final também são realizadas três atividades de verificação da aquisição do conhecimento:

a) Relacionar o fonema ao som inicial da palavra (com apoio visual e auditivo)

b) Relacionar o som inicial de palavra referência com uma opção de quatro outras palavras (sempre com apoio visual e auditivo) 
c) Relacionar o som inicial de diversos objetos com um fonema determinado.

Como premiação ao finalizar, é disponibilizado também um desenho do personagem Dom para colorir. Essa premiação foi escolhida pelas próprias crianças que participaram do teste piloto do jogo. Além do uso do jogo, são propostas atividades cinestésicas para sala de aula, com abordagem concreta, fornecendo uma nova possibilidade de fixação do aprendizado. Para essas abordagens é fornecido plano de aula completo, indicando objetivo, materiais, metodologia. São sempre trabalhados os mesmos fonemas do mundo, de maneira concreta, através da construção das letras em materiais como argila, colagens, gravetos etc.

\subsection{Complementariedade}

A proposta do Programa Domlexia não é a substituição do método de alfabetização já utilizado pela escola e pelos seus professores, mas sim um trabalho em paralelo, que trará uma base mais sólida para a aquisição da leitura e escrita, através da ampliação da consciência fonológica dos alunos.

\subsection{Identificação Precoce}

O Programa tem também como objetivo a identificação precoce das dificuldades de aprendizado, permitindo intervenções mais cedo, e consequentemente uma maior probabilidade de resultados positivos dessas intervenções.

Em seu panorama sobre identificação e prevenção precoces de dificuldades em leitura, Lyytinen e Erskine destacam a importante questão das dificuldades de aprendizagem não resolvidas e da falta de motivação subsequente como resultado do fracasso. Sem tratamento adequado e eficaz, apenas uma minoria das crianças que têm dificuldades de leitura alcança níveis satisfatórios como leitores [Fielding-Barnsley 2019]. LINK PARA O VÍDEO

\section{Resultados}

Turmas piloto realizadas nos meses de junho e julho de 2018, com 47 alunos do $1^{\circ}$ ano do Ensino Fundamental da Rede Municipal de Florianópolis, mostraram resultados consistentes de melhora na consciência fonológica, elevando os índices de acerto de $59 \%$ para $92 \%$ no teste de consciência fonêmica. Sendo que os demais testes também apresentaram melhoras, conforme demonstrado no gráfico a seguir.

O Programa Domlexia tem como foco a intervenção efetiva nas dificuldades e transtornos de aprendizagem. O objetivo é fazer com que os alunos se apropriem da alfabetização através de um método facilitador, que é o método fônico, de uma forma lúdica. O jogo é o motivador, mas a estrutura do Programa, com avaliação e atividades complementares, facilita para o professor a identificação e intervenção precoce para melhor ajudar as crianças com dificuldades de aprendizagem. 


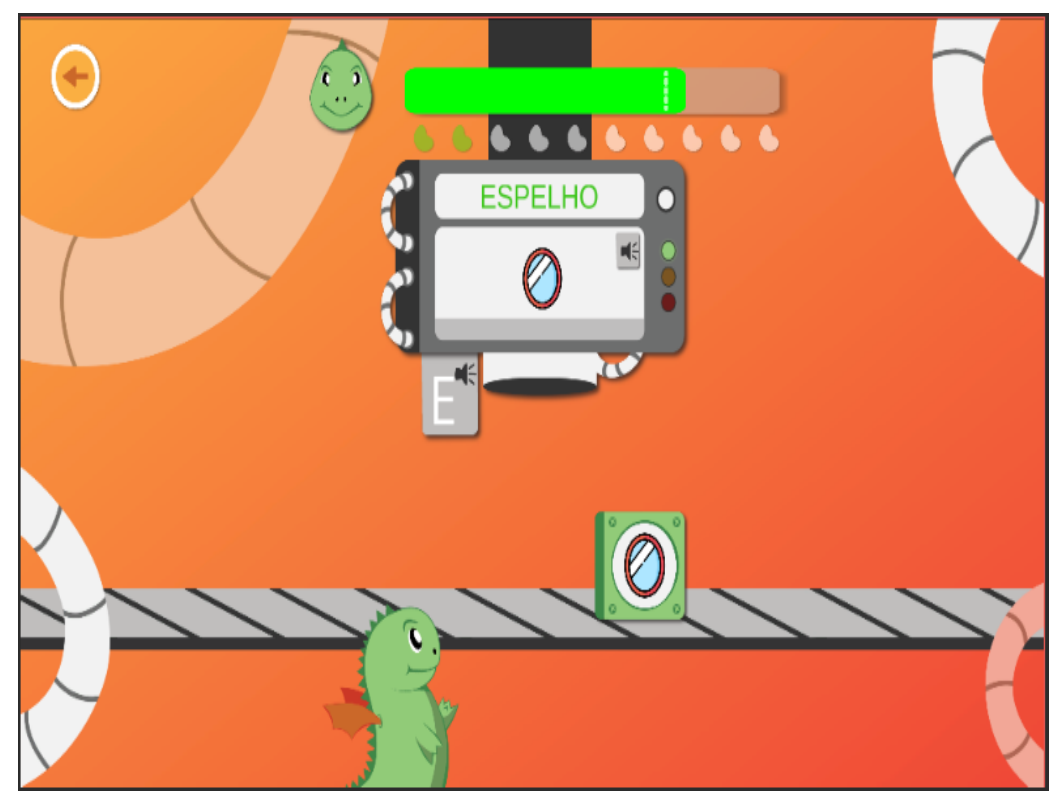

Figura 2: Jogo Dom e as letras

\section{Gráfico 1: Porcentagem de acertos nos testes antes e depois do uso do APP Dom}



\section{Referências}

Brasil (2018). "Base Nacional Comum Curricular". Ministério da Educação. Brasília:MEC. Acesso em 03 de junho de 2019: http://basenacionalcomum.mec.gov.br/images/BNCC_EI_EF_110518_versaofinal_si te.pdf

Brasil (2019). “Avaliação Nacional de Alfabetização". Brasília:INEP. Acesso em 05 de julho de 2019: http://ana.inep.gov.br

Ellis, A. W. (1995) "Leitura, escrita e dislexia: uma analise cognitiva". 2. ed. Trad. Dayse Batista. Porto Alegre: Artes Médicas.

Capovilla, F., Seabra, A. G.(2010) “Alfabetização: Método Fônico”. 5. ed. São Paulo: Memmon. 
Chall, J. (1996) "Learning to Read: The Great Debate (1967)", Edit by McGraw Hill, New York.

Clarck, D. B. et.al. (1995) "Dyslexia: Theory and Practice of Remedial Instruction". York Press.

Coulter, W. A. and Kaloi, L. (2013) “ Diplomas at Risk: A Critical Look at the Graduation Rate of Students with Learning Disabilities" https://www.advocacyinstitute.org/resources/Diplomas.at.Risk.pdf

Fielding-Barnsley R (2019) "Prevenção precoce de distúrbios de aprendizagem: comentários sobre Lyytinen e Erskine, e Fuchs" In: Tremblay RE, Boivin M, Peters RDeV,http://www.enciclopedia-crianca.com/disturbios-de-

aprendizagem/segundo- especialistas/prevencao-precoce-de-disturbios-deaprendizagem.

Hennig, K. A.(2003) “Compreender a dislexia um guia para os pais e professores". Porto Editora.

McCandliss B.D and Noble KG (2003) "The development of reading impairment: A cognitive neuroscience model. Mental Retardation and Developmental Disabilies”, In: Research Views 9: 196-205.

Piaget, J. (1998) “A psicologia da criança”. Edited by Bertrand Brasil, Rio de Janeiro.

QEdu (2019) "Prova Brasil". Acesso em 12 de julho de 2019: https://www.qedu.org.br/brasil/proficiencia

Rack, J. (2005) "The Incidence of Hidden Disabilities in the Prison Population". The Dyslexia Institute., 1-28.

Santos, C.R. (2018) “Alfabtização: Algumas reflexões sobre o método fônico e o método construtivista". Revista Conedu , v. 1, p. 1.

Savage, J.F. (2015) “Aprender a ler e a escrever a partir da fônica”, Edit by: McGrawHill $4^{\mathrm{a}}$ ed, Porto Alegre.

Schank, R. (2019) "Learning occurs when someone wants to learn, not someone wants to teach" https://www.rogerschank.com/

Vigotski, L.S. (2001) “A construção do pensamento e da linguagem”. Edited by Martins Fontes, São Paulo. 